\title{
Pathophysiology of Extravascular Water in the Pleural Cavity and in the Lung Interstitium After Lung Thoracic Surgery
}

\author{
Giuseppe Miserocchi and Egidio Beretta \\ University of Milano-Bicocca, Department of Experimental Medicine, \\ Italy
}

\section{Introduction}

Thoracic surgery implies a considerable imbalance of fluid dynamics in the pleural space and in the lung interstitium, and this is of relevance when considering that the volume of water in these compartments is physiologically very low thanks to very powerful mechanisms of control able to offset potential causes leading to an increase in this volume. There are reasons to believe that severe complications of lung fluid balance may occur after lung resection surgery and that the critical period is $24-48$ hours after intervention. This paper wishes to present an updated review of pathophysiology of fluid balance in the respiratory system to be discussed within the specific frame of lung resection surgery. Some concept were only marginally considered in a paper previously published that was mostly dedicated to alterations in respiratory mechanics following lung resection surgery (Miserocchi et al, 2010).

\section{Control of pleural liquid volume}

Pleural fluid turnover occurs at parietal pleural level in physiological conditions: a pressure gradient causes fluid to filter from the capillaries of the parietal pleura into the cavity and is drained through the lymphatics stomata that connect the pleural space to the submesothelial lymphatic network of the parietal pleura itself (Miserocchi \& Negrini, 1997).

Fig.1 highlights schematically that fluid filtration mostly occurs in less dependent regions and pleural fluid is drained towards preferential absorption sites at the bottom and in the mediastinal region. The absorption pressure of lymphatics (Fig. 2) sets a subatmospheric pressure of the pleural fluid that averages $\sim-10 \mathrm{cmH}_{2} \mathrm{O}$ at mid heart level (it is more negative in the less dependent regions of the cavity and less negative at the bottom, where it reaches $\sim 0 \mathrm{cmH}_{2} \mathrm{O}$ ). This pressure acts to keep the lung in close apposition of the chest wall. Note that the lung and the chest wall develop an elastic recoil that would tend to pull them apart (red arrows in the insert in Fig. 2), however, the pressure generated by such recoil (about $4 \mathrm{cmH}_{2} \mathrm{O}$ at the functional residual capacity) is less subatmospheric than that generated by the lymphatic pump, therefore, lung and chest wall are actually pushing one against the other. This mechanical condition does not impair the reciprocal movements of the parietal and visceral pleura (about $25000 \mathrm{~km}$ in a life span) due to a very efficient lubrication system (see insert in Fig.2) based on reciprocal repulsive forces of negative charges carried by polar phospholipids adsorbed on the opposing pleural surfaces and assures a friction coefficient as low as 0.02 (comparable to that of ice on ice) (Hills, 1992). 


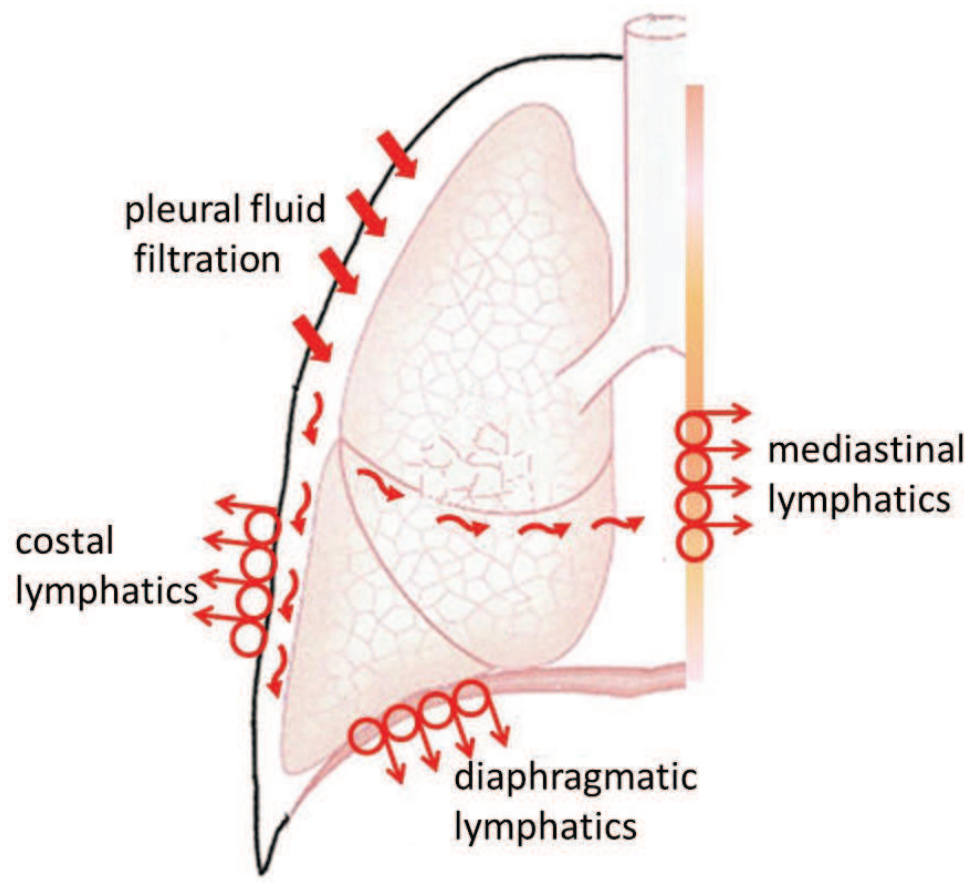

Fig. 1. Fluid turnover in the pleural cavity.

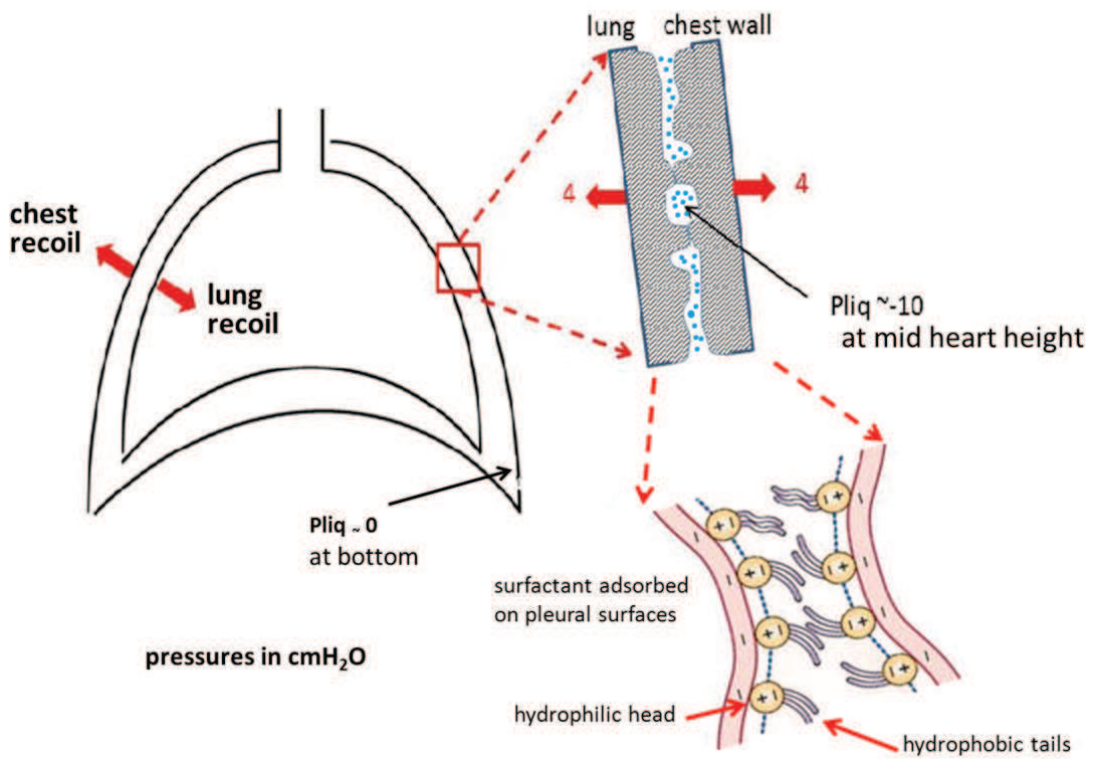

Fig. 2. Mechanical coupling between lung and chest wall. 


\subsection{Pathophysiology of pleural effusion}

Pleural lymphatics act as efficient regulators of pleural liquid volume avoiding hydrothorax formation by increasing the draining flow (up to $\sim 20$ fold) in proportion to the increase in filtration rate (Miserocchi, 2009). As a matter of fact, for a tenfold increase in filtration rate, the volume of the pleural fluid would only be hardly doubled (Miserocchi, 2009). Any increase in pleural fluid filtration can in principle easily accumulate in the chest due to the opposite retraction of the lung and chest wall (Fig. 3).

When filtration exceeds the maximum lymphatic flow, pleural effusion results favoured by three conditions: an increase in systemic capillary pressure, an increase in permeability of the parietal/visceral pleura, a strong limitation to an increase in lymphatic flow. Pleural effusion are classified as exudates when the fluid/serum total protein ratio (indicated as TPR) exceeds 0.5 (Joseph et al, 2001; Joseph et al, 2002; Joseph et al, 2003). The degree of mesothelial lesion can be related to the concentration of lactic dehydrogenase (Joseph et al,2001) in the pleural fluid (indicated as FLDH); a cut off for FLDH at 163-200 U/L has been proposed for diagnostic.

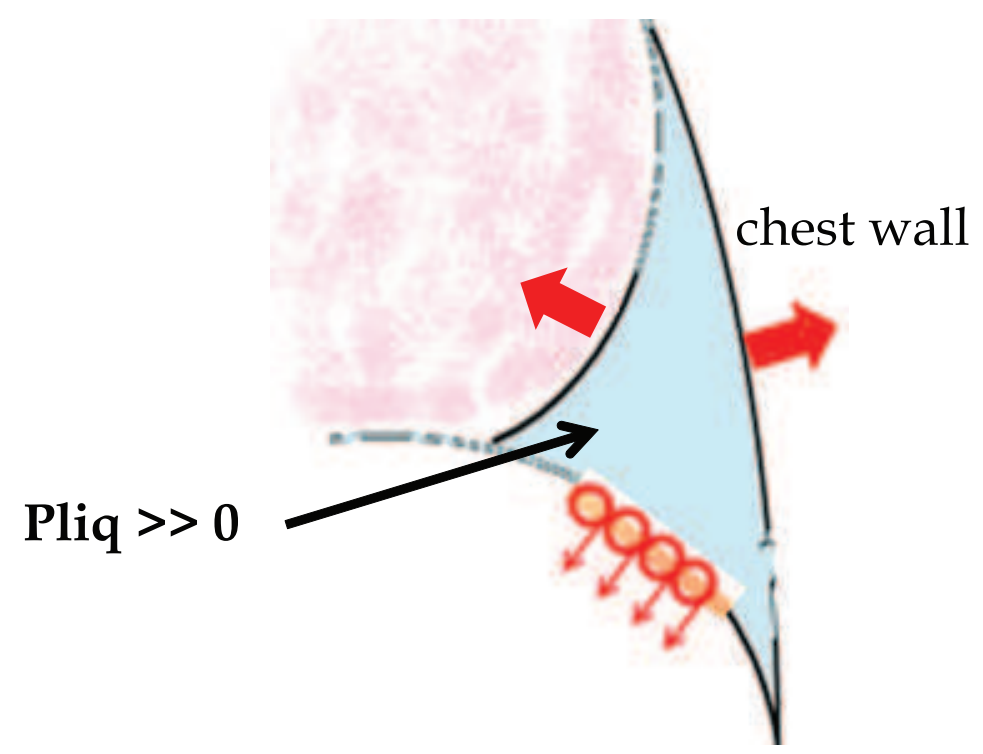

Fig. 3. Pleural lymphatics act as efficient regulators of pleural liquid volume.

\section{Control of extravascular water volume}

The thinness of the air-blood barrier (0.2-0.3 microns) reflects a functionally "dry" condition (Conforti et al, 2002), therefore, as much as for the pleural liquid, also for the extravascular space of the lung one can speak of a "minimum" volume of water. This ensures, in turn, a high efficiency of the gas diffusion. Similarly to the pleural fluid, also lung interstitial fluid is kept at a subatmospheric pressure (also $\sim-10 \mathrm{cmH}_{2} \mathrm{O}$, Fig.4) due to the powerful draining action of lymphatics in face of a very low microvascular permeability (Miserocchi, 2009). The latter feature allows to keep microvascular filtration as low as $1 \cdot 10^{-4} \mathrm{ml} / \mathrm{cm}^{2}$ in $24 \mathrm{~h}$. Fig. 4 also presents important molecules, belonging to the proteoglycans (PGs) family, 
whose role appears crucial to control the extravascular water volume, as they act as highy hydroplhilic link proteins. Perlecan, an heparansulphate PG (MW 0.1-0.5 MDa) is placed in the basement membrane and controls the porosity to water and solutes; versican (MW 0.5 $\mathrm{MDa}$ ), a large PG bound to hyaluronan (a random coiled molecule), provides rigidity to the tissue by establishing multiple non-covalent links with other molecules of the matrix and with cells (Roberts et al, 1997).

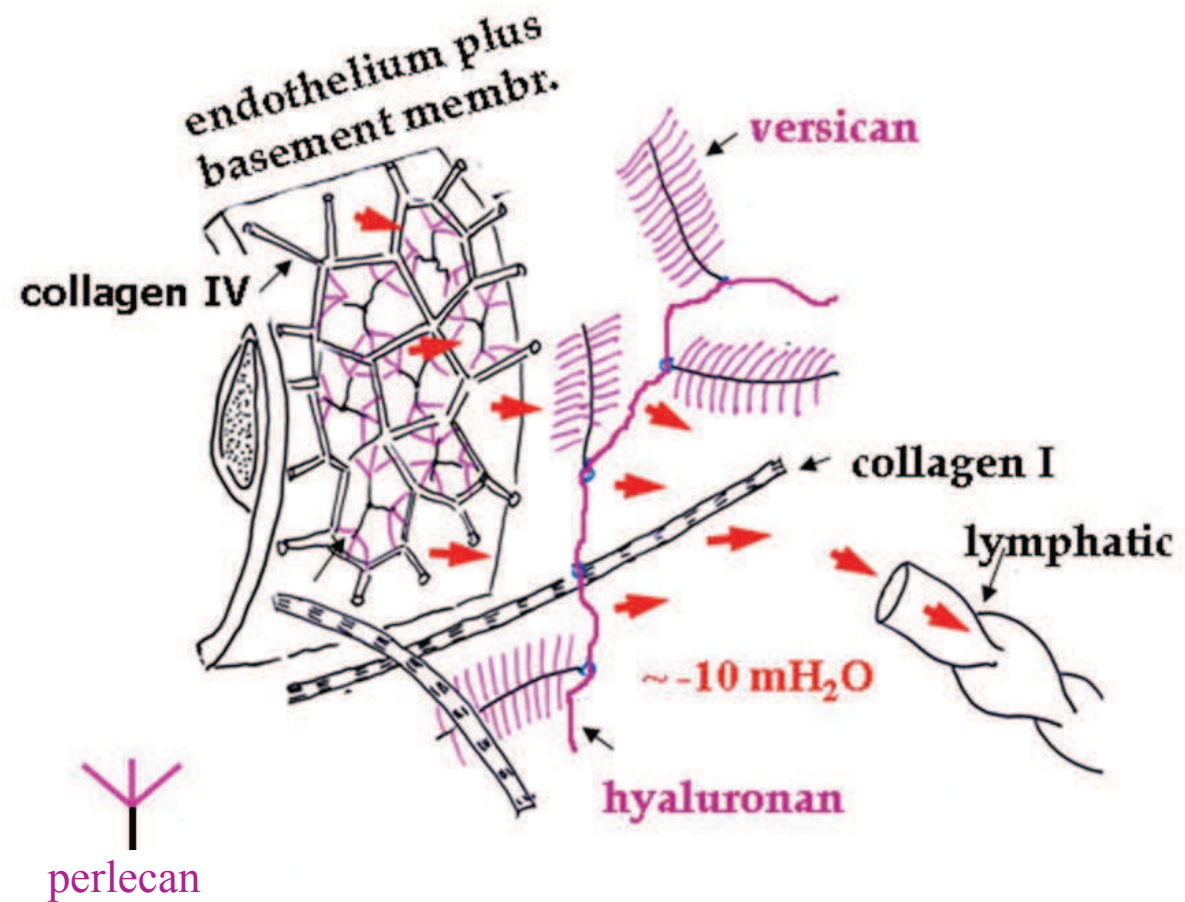

Fig. 4. Lung interstitial fluid dynamics and some macromolecular components of the interstitial matrix.

The volume of the extravascular water is strictly controlled so that the lung appears quite resistant to the development of edema. In fact, at least three mechanisms cooperate to allow only minimal variations in extravascular water volume relative to the steady state condition (Miserocchi, 2009). First, the glycosaminoglycan chains of PGs can bind excess water to form gel-like structures; this results in an increase in the steric hindrance of proteoglycans and corresponding decrease in the porosity of the basement membrane and thus also in microvascular permeability. Second, the assembly of large matrix PGs within the extracellular matrix provides low tissue compliance and this represents an important "tissue safety factor" against the development of edema. In fact, a minor increase in extravascular water in response to increased microvascular filtration, causes a marked increase in interstitial pressure (e.g., from $\sim-10$ to $\sim 5 \mathrm{cmH}_{2} \mathrm{O}$ ) (Miserocchi, 2009) that buffers further filtration. Third, arteriolar vasoconstriction represents an important reflex to avoid or actually decrease capillary pressure when filtration is increased due to an increase in microvascular permeability (Negrini, 1995, Rivolta et al, 2011). 


\section{Pathophysiology of lung edema}

The development of severe edema is known as a tumultuous event taking place in minutes (Miserocchi et al, 2001a). Experimental models in animals allowed to attribute the sudden increase in extravascular lung water (Miserocchi et al, 2001a) to the loss of integrity of the proteoglycan components of the macromolecular structure of the lung interstitial space. Fragmentation/degradation of PGs of the basement membrane cause an increase in microvascular permeability of the paracellular pathway as pore size can reach $50-100 \mathrm{~nm}$ allowing easy leak of albumin. Finding of red blood cells in the alveolar fluid reflects major lesions of the air blood barrier. Fragmentation of matrix PGs removes the "tissue safety factor" by causing an increase in interstitial compliance. The loss of integrity of PGs reflects the sustained increase in parenchymal stresses, the weakening of the non-covalent bonds due to increased water binding, and the activation of tissue metalloproteases (Miserocchi et al, 2001a).

One shall consider interstitial edema as a sharp edge between tissue repair and severe disease: in fact, the transition from interstitial to severe lung edema occurs through an "accelerated" phase when the loss of integrity of the interstitial matrix proceeds beyond a critical threshold. Interestingly, the same pathophysiological mechanism can be extended to all forms of lung edema, the only difference being the time sequence of fragmentation of the families of PGs. The initial degradation process involves the large matrix PGs in cardiogenic edema, while in the lesional edema model, the initial process involves PGs of the basement membrane. In the hypoxia lung edema model, both PGs families are involved (Miserocchi et al, 2001a). Lung cellular activation for matrix remodelling and repair was documented as differential expression of signalling-transduction platforms on plasma membrane (Sabbadini et al, 2003; Palestini et al, 2002; Palestini et al, 2003; Daffara et al, 2004; Botto et al, 2006; Botto et al, 2008) and the hypothesis was put forward of differential activations of these platforms (lipid rafts or caveolae) to trigger redeposition of specific matrix components. A further peculiar feature of lung edema is that to develop in a patchy way, thus revealing regional differences in the efficiency of control of extravascular water volume. These differences have been recently documented in a hypoxic edema model (Rivolta et al, 2011) and the hypothesis was put forward that alterations in the geometry of the microvascular-alveolar design might favor an imbalance in interstitial fluid dynamics.

\section{Specific conditions pertaining to thoracic surgery as potential causes of disturbance in extravascular water fluid dynamics}

\subsection{Pleural space}

Evacuation of air from the cavity is the most immediate problem after thoracic surgery to allow re-expansion of the remaining lung. Air (and fluid) drainage are accomplished via a chest tube placement, and we address the reader to a recently published consensus definition (Brunelli et al, 2011). As a matter of fact, tube management is basically left to personal surgeon's evaluation despite the fact that such practice is a major factor affecting the length of recovery, the cost and the morbidity of patients undergoing lung resection surgery. Many surgeons use only a single drain, likely differently oriented, to drain both air and pleural fluid. The initial gas drainage is better performed by having the chest tube opening placed in the retrosternal region where air collects in the supine posture (see 
below). Conversely, pleural fluid is profitably drained by having the tube opening in the lowermost part of the pleural space (dorsal costodiaphragmatic sinus, both in supine and head up posture (Miserocchi et al, 1988; Haber et al, 2001) where fluid collects. Hydrothorax may develop due to surgical insult and/or to excessive subatmospehric pressure applied to the chest tube favouring fluid filtration. Note that pleural liquid pressure in the costodiaphragmatic sinus is close to $0 \mathrm{cmH}_{2} \mathrm{O}$ in physiological conditions and may become positive with increasing liquid pooling.

Thus, the recommended strategy is simply that of having the chest tube open to atmosphere (Fig. 5A): whenever pressure, in the hydrothorax will exceed atmospheric pressure fluid will drain into the tube. To avoid suction of liquid/air back into the pleural cavity when a subatmospheric pleural pressure is generated on inspiration, a one way valve should be placed on the tube outlet. In case fluid advances down the tube (by $10 \mathrm{~cm}$ in Fig. 5B) a subatmospheric pressure $\left(-10 \mathrm{cmH}_{2} \mathrm{O}\right)$ is generated at tip of chest tube in the pleural space, a condition speeding up the drainage.

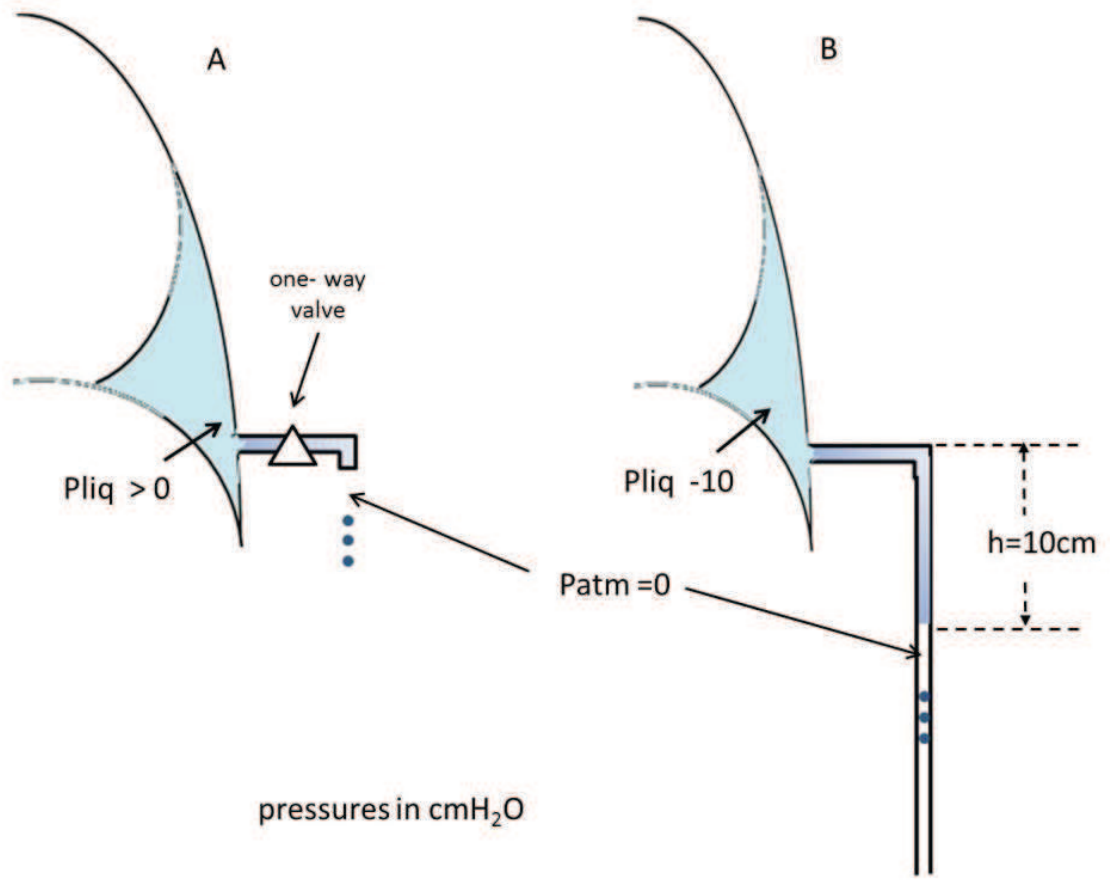

Fig. 5. Fluid mechanics of hydrothorax drainage from the costodiaphragmatic sinus.

For a pressure at tip of the order of about $-60 \mathrm{cmH}_{2} \mathrm{O}$ (the case of a fluid column from patient bed down to the floor) the pressure gradient for fluid filtration into the cavity would be increased by about 10 times! No wonder that such pressure would contribute to increased fluid filtration and hydrothorax formation. Interestingly, the negative pressure generated at tip remains basically confined to the fluid pool and is not transmitted to the rest of the pleural space due to the extremely high flow resistance of the pleural space once the visceral pleura adheres to the parietal one (Miserocchi et al, 1992). Recovery from 
pleural effusion may be slow, ranging from weeks to months (Cohen \& Sahn, 2001). Removal of chest tubes after fluid drainage of 400-450 cc /day or less appears reasonable (Cerfolio \& Bryant, 2008; Cerfolio et al, 2010; Bertholet et al 2010) as it is in the range of physiological daily pleural fluid filtration (an estimated value of $350 \mathrm{ml} /$ day (Miserocchi \& Negrini, 1997).

\subsection{Lung interstitium}

The important point to be considered here is that the compliance $(\Delta \mathrm{V} / \Delta \mathrm{P})$ of the remaining lung is decreased in proportion to the amount of the resected portion: so, for example, a $50 \%$ reduction in lung volume, would entrain a similar reduction in lung compliance.
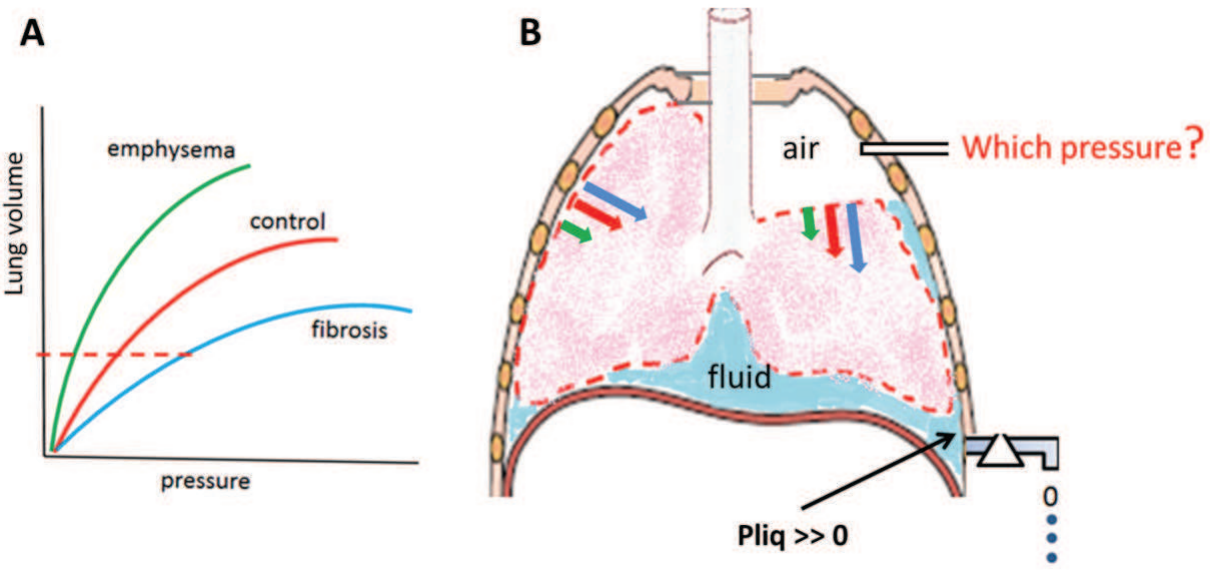

Fig. 6. Safe strategy to re-expand the lung after resection: gas pressure must generate the pre- operation lung distending pressure that depends upon the functional state of the lung.

Therefore re-expansion of the remaining lung to match the original chest volume would obviously require considerable greater distending pressure (over-distension) as well as a remarkable deformation of its natural shape. As thoroughly discussed in a previous paper (Miserocchi et al, 2010), to avoid lung over-distension re-expansion of the remaining lung should match the pre-operating distending pleural pressure that vary however as described by the volume-pressure relationship (Fig. 6A): fibrosis (blue) increases lung distending pressures on the abscissa and decreases compliance, while the opposite occurs in emphysema (green), relative to control (red). In practice, an air bubble ought to remain in the pleural cavity and the pressure generated by the suction line (Fig.6B) must be equal to that exerted by the lung before resection. The elastic properties of the lung can be described during a pneumological functional examination by relating lung volumes to the corresponding values of transpulmonary pressures as deduced from oesophageal pressure.

\section{Lung over-distension: The risks of air leak and lung edema}

\subsection{Air leak}

If no leaks are present, the gas bubble is reabsorbed ( $1 \% /$ day), following the gradient in gas partial pressures in the blood and in the gas phase, until physical equilibration is 
reached. Reabsorption of the gas bubble is initially slow because the flow of $\mathrm{O}_{2}$ to the blood is opposed by $\mathrm{CO}_{2}$ flow to the bubble; furthermore, $\mathrm{N}_{2}$ slows down the reabsorption process because of its low solubility in blood. Washing the cavity with oxygen would speed up the reabsorption process. The corresponding decrease in pleural pressure would increase fluid filtration so that, over time, liquid will replace gas.

Air leak after pulmonary resection may be due to bronchopleural or bronchoalveolarpleural fistulas (Rice et al, 2002) due to failure to obtain a perfect surgical seal. An estimate of air leak would be useful to decide about chest drainage removal, however the methods of detecting air bubbles along the chest tube during forced expiratory maneuvers appears rather imprecise, while more refined methods are available (Varela et al, 2009). Measuring the change in pressure in the air bubble $(\Delta \mathrm{P})$ by a chest tube would allow an indirect estimate of the change in air volume $(\Delta \mathrm{V})$ considering that $\Delta \mathrm{V}=\mathrm{Crs}{ }^{*} \Delta \mathrm{P}$, where $\mathrm{Crs}$ is the compliance of the respiratory system. Considering the mechanical arrangement of the lung and of the chest wall, one has:

$$
\frac{1}{C r s}=\frac{1}{C l}+\frac{1}{C w}
$$

where $\mathrm{Cl}$ and $\mathrm{Cw}$ are the compliance of lung and chest wall respectively. In physiological conditions, one has $\mathrm{Cl}=\mathrm{Cw}=0.2 \mathrm{~L} / \mathrm{cmH}_{2} \mathrm{O}$, so that one has $\mathrm{Crs}=0.1 \mathrm{Cl}$. As mentioned above, $\mathrm{Cl}$ reflects the functional state of the lung and furthermore is decreased in proportion of the decrease in lung volume. No such measurements are considered so far in the clinical practice: yet, we believe that a pneumological functional evaluation would provide important information concerning the trend of an air leak.

\subsection{Lung edema}

Severe complications representing the major cause of morbidity after lung resection ("idiopathic edema", ALI, atelectasis, ARDS) share a similar patho-physiological basis essentially represented by an acute increase in microvascular filtration, thus, simply, edema formation (Miserocchi et al, 2010). In post lung resection surgery, this can be due to:

- lung overinflation on re-expansion and/or prolonged mechanical ventilation with excessive tidal volume (Miserocchi et al, 1991). Stretching of lung parenchyma results indeed in a marked subatmospheric interstitial pressure, that, in turn, favours microvascular filtration potentially evolving towards matrix fragmentation and an "accelerated phase" (Miserocchi et al, 2001a);

- lack of clearance of the fragments, neutrophil and macrophage activation (Adair-Kirk \& Senior, 2008), production of reactive oxygen species, leading to diffuse alveolar damage and inhibition of the active alveolar fluid reabsorption (Khimenko et al, 1994);

- large amounts of intraoperative fluid administration (Zeltin et al, 1984; Slinger, 2006), particularly when coupled to increased microvascular permeability, as clearly shown by experimental models of lung edema (Miserocchi et al, 2001a);

- the remaining lung is hosting a greater blood flow and this is accomplished by capillary recruitment and increased blood flow velocity and shear rate that lead to an increase in microvascular permeability (Min-Ho et al, 2005);

- local hypoxia, a known factor favouring edema formation (Miserocchi et al, 2001b), may develop due to edema itself as well as to ventilation/perfusion mismatch; 
- finally, due to the decrease in vascular bed, pulmonary vascular resistances are likely to increase leading to pulmonary hypertension that is potentially correlated to the risk of developing pulmonary edema (Grünig et al, 2000; Rivolta et al, 2011).

\section{The "postoperative residual pleural space"}

The "postoperative residual pleural space" refers to the fate of the volume left free by lung resection (Misthos et al, 2007). As much as in physiological conditions, the main variable setting the volume of the postoperative residual pleural space is the absorption pressure of the pleural lymphatics. If their capacity to drain flow and generate a subatmospheric pressure have remained unchanged, they will still tend to reduce pleural liquid volume to a minimum. However, the new "minimum" will reflect a state equilibrium resulting from the modified lung-chest wall coupling and the actual filtration/absorption balance of pleural fluid. In practice, the volume left free by lung resection will be occupied (Fig. 7) in part by pleural fluid, in part by an increase in volume of the remaining lung, and in part by the displacement of the diaphragm and of the mediastinum.

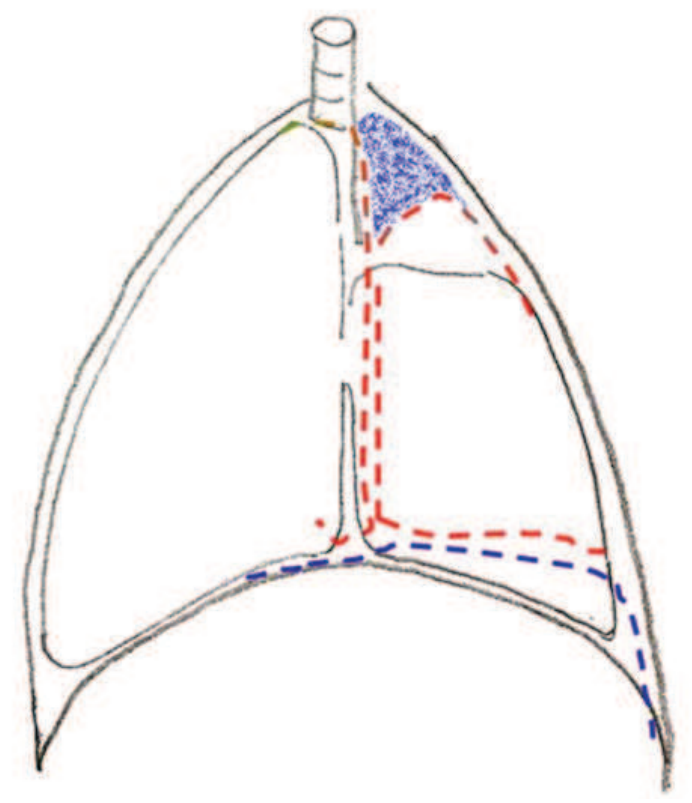

Fig. 7. The "postoperative residual pleural space" (blue area).

\section{Cardiac output, lung fluid-balance and oxygen diffusion-transport}

As delineated in section 2, control mechanisms are present in the lung to limit the increase in extravascular volume such as when lung capillary recruitment occurs in response to an increase in cardiac output. However the efficiency of these mechanisms, as from experimental models, varies among lung regions and among individuals, particularly when tissue hypoxia is also present (Rivolta et al, 2011). 
A

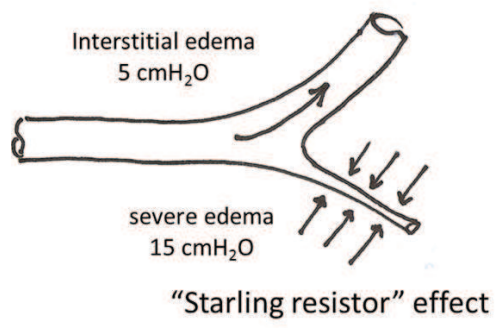

B

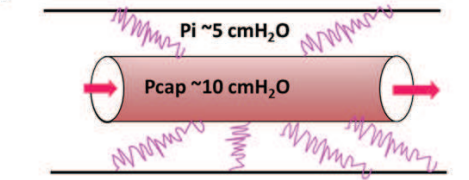

Interstitial edema: Integrity of proteoglycans link proteins assures capillary patency

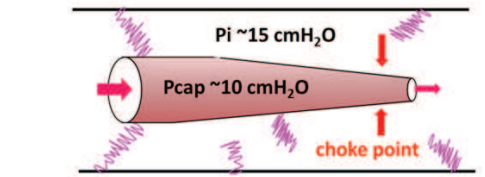

Severe lung edema: Loss of integrity of the matrix, capillary compression

Fig. 8. A: lung capillary squeeze in relation to interstitial fluid pressure ("Starling resistor" effect). B: role of proteoglycans (in pink) fragmentation in favouring the squeeze of microvessels in severe edema.

Fig. 8A shows that in regions where severe edema develops, the increase in interstitial pressure is such as to squeeze the microcirculation ("Starling resistor" effect) thus impairing blood flow (Rivolta et al, 2011). In fact, the patency of microvessels is critically dependent upon the integrity of the proteoglycan molecules linking the matrix to the endothelial surface: as suggested in Fig. 8B, the integrity is preserved in interstitial edema, while massive fragmentation occurs when severe edema develops. The decrease in vascular bed causes a rise in pulmonary vascular resistances leading to an increase in pulmonary artery pressure, whose entity reflects the extension of severe edema (Rivolta et al, 2011). The variability concerning the proneness to develop lung edema and associated pulmonary hypertension in response to an increase in cardiac output, particularly when associated with alveolar hypoxia, is documented not only in animals but also in humans (Grünig et al, 2000). One can now remark that after resection surgery, the remaining lung, as described in section 4.2, is also exposed to increased blood flow and, owing to potential ventilation/perfusion mismatch, also to local hypoxia. Therefore, the risk of developing post-lung resection surgery pulmonary edema may depend upon the extension of the resection as well as on the individual proneness to develop lung edema. It appears therefore justified to assess the latter point by performing a pre-operation cardio-pulmonary exercise test and gather data on cardiac output, pulmonary artery pressure, pulmonary vascular resistance as well as indirect evidence of increase in lung water (see paragraph 7 below). These data may be compared to post-resection surgery condition.

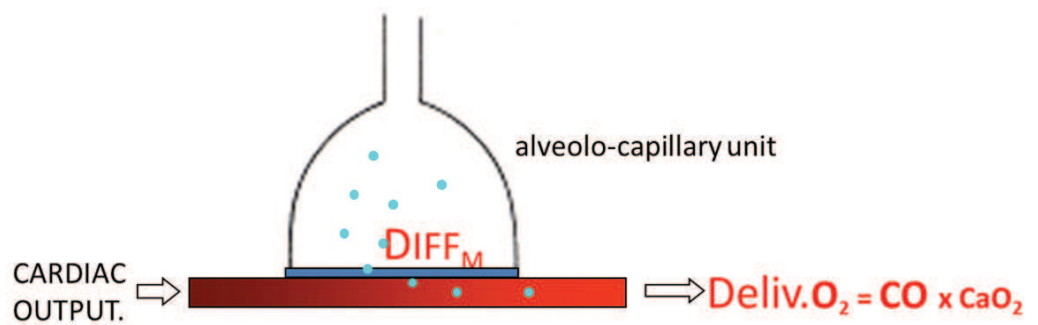

Fig. 9. Lung water balance related mechanisms limiting oxygen delivery 
Fig. 9 summarizes the lung-water balance related mechanisms that may limit oxygen delivery defined as DelivO $\mathrm{O}_{2}=$ Cardiac Output $\times \mathrm{CaO}_{2}$, where $\mathrm{CaO}_{2}$ is the oxygen concentration at the lung capillary outlet. A membrane "diffusion limitation" (DIFFM) may result from the reduction in alveolar surface available for diffusion and/or from the presence of edema fluid. "Perfusion limitation" in oxygen transport has also to be envisaged because $\mathrm{DelivO}_{2}$ is critically dependent upon regional lung blood flow and this, in turn, depends upon the local patency-compression condition of microvessels (see Fig. 8). Finally, the increase in blood flow velocity slows down the alveolo-capillary oxygen equilibration. All together, these alterations result in an alveolo-capillary oxygen pressure difference.

\section{Indexes to assess alteration in pleural and lung interstitial fluid balance}

Most of the complications of post-thoracic surgery relate to a severe disturbance in lung extravascular water and occur in the early postoperative period (Alvarez et al, 2007; Khan et al, 1999), similarly to what is observed after lung transplant (Khan et al, 1999).

Pre-operative:

- lung compliance: needs measurement of transpulmonary pressure by using an esophageal balloon (more easily performed once the patient is anesthetized)

- lung diffusion DLCO, Krogh factor (DLCO/alveolar volume). After lung resection DLCO will be reduced in proportion of resected volume, however, if the remaining lung works as an efficient diffusor, the Krogh factor will be normal.

- respiratory impedance (in particular reactance at low oscillation frequency , $1 \mathrm{~Hz}$ ). A recent paper highlights that reactance significantly decreases for an increase in extravascular water of about $10 \%$ (Dellacà et al, 2008).

- lung comets determined by echocardiography, as a sign of interstitial lung edema (Picano et al, 2006).

- cardio-pulmonary exercise test to evaluate the efficiency of the oxygen diffusiontransport system and the proneness to develop pulmonary edema

Immediate Post-operative:

- measure lung compliance at the end of operation while the patient is still under anaesthesia

- $\quad$ sensitive methods to assess a disturbance in lung fluid (respiratory impedance, comets)

- time course of pressure in the pleural air bubble to monitor the trend of a potential air leak

- $\quad$ lung diffusion: DLCO, Krogh factor (DLCO/alveolar volume)

\section{Later on:}

- cardio-pulmonary exercise test to evaluate the efficiency of the oxygen diffusiontransport system

\section{References}

Adair-Kirk T.L. \& Senior R.M. (2008). Fragments of extracellular matrix as mediators of inflammation. Int J Bioch. Cell Biol, Vol.40, pp. 1101-1110.

Alvarez JM, Tan J, Kejriwal N, Ghanim, K., Newman, M.A., Segal, A., Sterret, G. \& Bulsara, M.K. (2007). Idiopathic postpneumonectomy pulmonary edema: Hyperinflation of the remaining lung is a potential etiologic factor, but the condition can be averted by balanced pleural drainage. J Thorac Cardiovasc Surg, Vol. 133, pp. 1439-4147. 
Bertholet, J.W., Joosten J.J., Keemers-Gels M.E., van den Wildenberg F.J. \& Barendregt W.B. (2010) Chest tube management following pulmonary lobectomy: change in protocol results in fewer air leaks. Interact Cardiovasc Thorac Surg, Vol. 12, No. 1, pp. 28-31.

Botto, L., Beretta, E., Bulbarelli, A., Rivolta I., Lettiero, B., Leone, B.E., Miserocchi, G. \& Palestini, P. (2008). Hypoxia-induced modifications in plasma membranes and lipid microdomains in A549 cells and primary human alveolar cells. J Cell Biochem, Vol. 105, No 2, pp. 503-513.

Botto, L., Beretta, E., Daffara, R., Miserocchi, G. \& Palestini P. (2006) Biochemical and morphological changes in endothelial cells in response to hypoxic interstitial edema. Respir Res, Vol. 7, No. 1, pp. 7.

Brunelli, A., Beretta, E., Cassivi, S.D., Cerfolio, R.J., Detterbeck, F., Kiefer, T., Miserocchi, G., Shrager, J., Singhal, S., Van Raemdonck, D. \& Varela, G. (2011). Consensus definitions to promote an evidence-based approach to management of the pleural space. A collaborative proposal by ESTS, AATS, STS, and GTSC. Eur J Cardiothorac Surg. Vol. 40(2), pp.291-297.

Cerfolio, R.J. \& Bryant, A.S. (2008). Results of a prospective algorithm to remove chest tubes after Pulmonary resection with high output. J Thorac Cardiovasc Surg, Vol. 135 pp. 269-273.

Cerfolio, R.J., Varela, G, \& Brunelli, A. (2010). Digital and smart chest drainage systems to monitor air leaks: the birth of a new era? Thorac Surg Clin, Vol. 20, pp. 413-420.

Cohen, M. \& Sahn, S.A. (2001). Resolution of Pleural Effusions. Chest, Vol. 119, pp. 15471562.

Conforti, E., Fenoglio, C., Bernocchi, G., Bruschi, O. \& Miserocchi, G. (2002). Morphofunctional analysis of lung tissue in mild interstitial edema. Am J Physiol (Lung Cell Mol Physiol), Vol. 282, pp. L766-L774.

Daffara, R., Botto, L., Beretta, E., Conforti, E., Faini, A., Palestini, P. \& Miserocchi, G. (2004). Endothelial cells as early sensors of pulmonary interstitial edema. J Appl Physiol, Vol. 97, No 4, pp. 1575-1583.

Dellacà, R.L., Zannin, E., Sancini, G., Rivolta, I., Leone, B,E,, Pedotti, A. \& Miserocchi, G. (2008). Changes in the mechanical properties of the respiratory system during the development of interstitial lung edema. Respir Res, Vol. 12, No. 9, pp. 51-60.

Grünig E., Mereles D., Hildebrandt W., Swenson E.R., Kübler W., Kuecherer H. \& Bärtsch P. (2000). Stress Doppler echocardiography for identification of susceptibility to high altitude pulmonary edema. J Am Coll Cardiol. Vol. 35, No. 4, pp. 980-987.

Haber, R., Grotberg, J.B., Glucksberg, M.R., Miserocchi, G., Venturoli, D., Del Fabbro, M. \& Waters CM. (2001). Steady-state pleural fluid flow and pressure and the effects of lung buoyancy. J Biomech Engineering, Vol. 124, pp. 485-492T

Hills, B.A. (1992). Graphite-like lubrication of mesothelium by oligolamellar pleural surfactant. J Appl Physiol, Vol. 73, pp. 1034-1039.

Joseph, J., Badrinath, P., Basran, G.S. \& Sahn, S.A. (2001). Is the pleural fluid transudate or exudate? A revisit of the diagnostic criteria. Thorax, Vol.56, pp. 867-870.

Joseph, J., Badrinath, P., Basran, G.S. \& Sahn, S.A. (2003). Do we need all three criteria for the diagnostic separation of pleural fluid into transudates and exudates? An appraisal of the traditional criteria. Med Sci Monit, Vol. 9, No. 11, pp. CR474-476. 
Joseph, J., Badrinath, P., Basran, G.S. \& Sahn, S.A. (2002). Is albumin gradient or fluid to serum albumin ratio better than the pleural fluid lactate dehydroginase in the diagnostic of separation of pleural effusion? BMC Pulmonary Medicine, Vol. 22, No. 2, pp. 1 .

Khan, S.U., Salloum, J., O'Donovan, P.B., Mascha, E.J., Mehta, A.C., Matthay, M.A. \& Arroliga, A.C. (1999). Acute Pulmonary Edema After Lung transplantation. Chest, Vol.116, pp. 187-194.

Khimenko, P.L., Barnard, J.W., Moore, T.M., Wilson, P.S., Ballard, S.T. \& Taylor, A.E. (1994). Vascular permeability and epithelial transport effects on lung edema formation in ischemia and reperfusion. J Appl Physiol, Vol. 77, No. 3, pp. 1116-1121.

Min-Ho, K., Harris, N.R. \& Tarbell, J.M. (2005). Regulation of capillary hydraulic conductivity in response to an acute change in shear. Am J Physiol Heart Circ Physiol, Vol. 289, pp. H2126-H2135.

Miserocchi, G., Negrini, D., Pistolesi, M., Bellina, C.R., Gilardi, M.C., Bettinardi, V. \& Rossitto F. Intrapleural liquid flow down a gravity dependent hydraulic pressure gradient. J Appl Physiol, Vol. 1988, No. 64, pp. 577-584.

Miserocchi, G., Negrini, D. \& Gonano, C. (1991). Parenchymal stress affects interstitial and pleural pressures in in situ lung. J Appl Physiol, Vol. 71, No. 5, pp. 1967-1972.

Miserocchi, G., Venturoli, D., Negrini, D., Gilardi, M.C. \& Bellina, R. (1992). Intrapleural fluid movements described by a porous flow model. J Appl Physiol, Vol. 73, pp. 2511-2516.

Miserocchi, G. \& Negrini, D. (1997). Pleural space: pressure and fluid dynamics, In: THE LUNG, Scientific Foundations, Crystal, R.G. West, J.B., Weibel, E.R. \& Barnes, P.J., pp. 1217-1225, Lippincott-Raven Pub, New York..

Miserocchi, G., Negrini, D., Passi, A. \& De Luca, G. (2001a). Development of lung edema: interstitial fluid dynamics and molecular structure. News Physiol Sci, Vol. 16, pp. 6671.

Miserocchi, G., Passi, A., Negrini, D., Del Fabbro, M. \& De Luca. (2001b). Pulmonary interstitial pressure and tissue matrix structure in acute hypoxia. Am J Physiol (Lung Cell Mol Physiol), Vol. 280, pp. L881-L887.

Miserocchi, G. (2009). Mechanisms controlling the volume of pleural liquid and extravascular lung water. Eur Respir Rev, Vol. 18, pp. 244-52.

Miserocchi, G., Beretta, E. \& Rivolta, I. (2010). Respiratory mechanics and fluid dynamics after lung resection surgery. Thorac Surg Clin, Vol. 20, pp. 345-357.

Misthos, P., Kokotsakis, J., Konstantinou, M., Skottis, I. \& Lioulias, A. (2007). Postoperative Residual Pleural Spaces: Characteristics and Natural History. Asian Cardiovasc Thorac Ann, Vol. 15, pp. 54-58.

Negrini, D. (1995). Pulmonary microvascular pressure profile during development of hydrostatic edema. Microcirculation, Vol. 2, pp. 173-180.

Palestini, P., Calvi, C., Conforti, E., Botto, L., Fenoglio, C. \& Miserocchi, G. (2002). Composition, biophysical properties and morphometry of plasma membranes in pulmonary interstitial edema. Am J Physiol Lung Cell Mol Physiol, Vol. 282, pp. L1382-L1390.

Palestini, P., Calvi ,C., Conforti, E., Daffara, R., Botto, L. \& Miserocchi, G. (2003). Compositional changes in lipid microdomains of air-blood barrier plasma membranes in pulmonary interstitial edema. J Appl Physiol, Vol. 95, pp. 1446-1452. 
Picano, E., Frassi, F., Agricola, E., Gligorova, S., Gargani, L. \& Mottola, G. (2006). Ultrasound lung comets: a clinically useful sign of extravascular lung water. J Am Soc Echocardiogr, Vol. 19, No. 3, pp. 356-363.

Rice, T.W., Okereke, I.C. \& Blackstone, E.H. (2002). Persistent air-leak following pulmonary resection. Chest Surg Clin N Am, Vol. 12, pp. 529-539.

Rivolta, I., Lucchini, V., Rocchetti, M., Kolar, F., Palazzo, F., Zaza, A. \& Miserocchi, G. (2011). Interstitial pressure and lung oedema in chronic hypoxia. Eur Respir J, Vol. 37, pp. 943-949.

Roberts, C.R., Wight, T.N. \& Hascall, V.C. (1997). Proteoglycans. In: The LUNG scientific foundtaions., Crystal, R.G. West, J.B., Weibel, E.R. \& Barnes, P.J. pp. 757-767, Lippincott-Raven Pub, New York.

Sabbadini, M., Barisani, D., Conforti, E., Marozzi, A., Ginelli, E., Miserocchi, G. \& Meneveri, R. (2003). Gene expression analysis in interstitial lung edema induced by saline infusion. Bioch Bioph Acta-Mol Basis of Dis, Vol. 1638, pp. 149-156.

Slinger, P.D. (2006). Postpneumonectomy pulmonary edema. Anesthesiology, Vol. 105, pp. 25.

Varela, G., Jimenez, M.F., Novoa, N.M. \& Aranda, J.L. (2009). Postoperative chest tube management: measuring air leak using an electronic device decreases variability in the clinical practice. Eur J Cardiothorac Surg, Vol. 35, pp. 28-31.

Zeldin, R.A., Normadin, D., Landwing, B.S. \& Peters, R.M. (1984). Postpenumonectomy pulmonary edema. J Thoracic Cardiovasc Surg, Vol. 87, pp. 359-365. 
TOpics w

THORACIC SURGERY

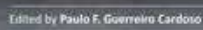

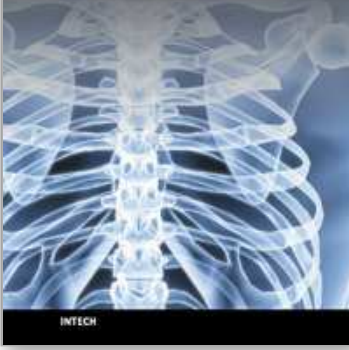

\section{Topics in Thoracic Surgery}

Edited by Prof. Paulo Cardoso

ISBN 978-953-51-0010-2

Hard cover, 486 pages

Publisher InTech

Published online 15, February, 2012

Published in print edition February, 2012

Thoracic Surgery congregates topics and articles from many renowned authors around the world covering several different topics. Unlike the usual textbooks, Thoracic Surgery is a conglomerate of different topics from Pre-operative Assessment, to Pulmonary Resection for Lung Cancer, chest wall procedures, lung cancer topics featuring aspects of VATS major pulmonary resections along with traditional topics such as Pancoast tumors and recurrence patterns of stage I lung disease, hyperhidrosis, bronchiectasis, lung transplantation and much more. This Open Access format is a novel method of sharing thoracic surgical information provided by authors worldwide and it is made accessible to everyone in an expedite way and with an excellent publishing quality.

\section{How to reference}

In order to correctly reference this scholarly work, feel free to copy and paste the following:

Giuseppe Miserocchi and Egidio Beretta (2012). Pathophysiology of Extravascular Water in the Pleural Cavity and in the Lung Interstitium After Lung Thoracic Surgery, Topics in Thoracic Surgery, Prof. Paulo Cardoso (Ed.), ISBN: 978-953-51-0010-2, InTech, Available from: http://www.intechopen.com/books/topics-in-thoracicsurgery/pathophysiology-of-extravascular-water-in-the-pleural-cavity-and-in-the-lung-interstitium-after-lung

\section{INTECH}

open science | open minds

\section{InTech Europe}

University Campus STeP Ri

Slavka Krautzeka 83/A

51000 Rijeka, Croatia

Phone: +385 (51) 770447

Fax: +385 (51) 686166

www.intechopen.com

\section{InTech China}

Unit 405, Office Block, Hotel Equatorial Shanghai

No.65, Yan An Road (West), Shanghai, 200040, China

中国上海市延安西路65号上海国际贵都大饭店办公楼 405 单元

Phone: +86-21-62489820

Fax: +86-21-62489821 
(C) 2012 The Author(s). Licensee IntechOpen. This is an open access article distributed under the terms of the Creative Commons Attribution 3.0 License, which permits unrestricted use, distribution, and reproduction in any medium, provided the original work is properly cited. 